TEMAS EMERGENTES

\title{
El derecho a manifestarse bajo la óptica de la ley antisaqueos
}

\author{
The right to protest under the perspective of anti-looting act \\ Mariana Bell Santos (iD) y Martín Fuentes Fernández (iD) \\ Universidad de Chile
}

\begin{abstract}
RESUMEN El presente trabajo tiene por objeto analizar las modificaciones legislativas introducidas en virtud de la Ley 21.208, que tipifica acciones que atenten contra la libertad de circulación de las personas en la vía pública a través de medios violentos e intimidatorios, y que se origina a propósito del denominado «estallido social chileno», con el objeto de proteger el orden público. Para ello, se emprende un análisis crítico de estas modificaciones sobre la base de los estándares internacionales en materia de derechos humanos a nivel interamericano, en relación con los requisitos que se exigen para la limitación del derecho a la protesta al interior de los órdenes democráticos contemporáneos. Dichos requisitos se analizan según el instrumento normativo en el que consta la limitación, la necesidad y la idoneidad de la medida. Se concluye que la implementación de este programa político-normativo de criminalización no solo es deficiente en términos de política legislativa; tampoco satisface los estándares internacionales existentes en la materia.
\end{abstract}

PALABRAS CLAVE Protesta social, desórdenes públicos, seguridad ciudadana, política criminal.

ABSTRACT The purpose of this work is to analyze the legislative modifications introduced by virtue of Law 21,208, that typifies actions that violate the freedom of movement of people on public roads through violent and intimidating means, and that originates within the so called «Chilean social outburst» with the aim to protect public order. To this end, a critical analysis of these modifications is undertaken based on international standards on human rights at the inter-American level, in relation to the requirements for limiting the right to protest within contemporary democratic orders. Said requirements are analyzed according to the normative instrument that contains the limitation, necessity and suitability of the measure. It is concluded that the implementation of this political-normative criminalization program is not only deficient in terms of legislative policy; neither does it satisfies the existing international standards on the matter. 
KEYWORDS Social protest, public disorders, citizen security, criminal policy.

\section{Introducción}

Durante 2005, el entonces presidente de Chile Ricardo Lagos esbozaba en una entrevista su posición respecto del tenso vínculo entre la protesta social y el orden democrático: privilegiar el funcionamiento de las instituciones. Catorce años después, el 20 de octubre de 2019, durante el desarrollo de lo que la prensa denominó en un principio «Revolución de la chaucha» y, con posterioridad, «estallido social», el presidente, esta vez Sebastián Piñera, señaló que Chile se encontraba en «guerra contra un enemigo poderoso, implacable, que no respeta a nada ni a nadie». Aun cuando la apelación al miedo constituye un recurso lingüístico más drástico, la idea que subyace es la misma tras las palabras del presidente Lagos: la necesidad de proteger a toda costa el orden institucional (Navarro y Tromben, 2019).

Es posible constatar la existencia de un discurso estructurado sobre la base de dos ideas en lo que concierne al resguardo del orden público y su fortalecimiento. En primer lugar, la necesidad de preservar el funcionamiento del orden institucional contra toda amenaza; la segunda, el recurso al miedo y otros dispositivos afines, con el fin de privilegiar una opción legislativa criminalizadora. Esto, por cierto, no resulta novedoso. Como bien se ha señalado por parte de la doctrina, dicha tendencia se ha consolidado desde 2010 hasta la fecha y se ha materializado en una serie de iniciativas legislativas cuyo propósito común ha sido la criminalización de las movilizaciones sociales, lo que ha acarreado la consiguiente hipertrofia de las herramientas punitivas del Estado en aras de la protección del orden público (Rojas y Valdés, 2013).

Considerando lo anterior, la publicación de la Ley 21.208, que «Modifica el Código Penal para tipificar acciones que atenten contra la libertad de circulación de las personas en la vía pública a través de medios violentos e intimidatorios, y fija las penas aplicables al saqueo en las circunstancias que indica», no constituye algo inusual en la producción normativa chilena tras episodios caracterizados por altos índices de conflictividad social.

Ello es a lo menos cuestionable desde una perspectiva internacional. De manera constante, los diversos actores interamericanos han tenido la oportunidad de pronunciarse sobre los estándares a los que debe sujetarse la intervención normativa que persiga la restricción de garantías fundamentales - especialmente cuando dicha intervención se sustenta sobre herramientas de índole punitiva-. Así, de forma sintética, se ha reafirmado la naturaleza excepcional de toda restricción y las condiciones sustantivas bajo las que es posible predicar de estas su legitimidad.

A partir de lo anterior, el objeto de nuestro trabajo es analizar la historia y las modificaciones legales que introduce en nuestro ordenamiento la ya referida Ley 21.208, 
respecto de la creación del tipo penal de interrupción a la libre circulación. Para ello, sin embargo, abordaremos de forma previa — desde una perspectiva más bien teórica- los problemas internos a la vinculatoriedad entre las manifestaciones públicas («el derecho a la protesta») y el ordenamiento jurídico. En un segundo orden de ideas, sentaremos los criterios internacionales acorde a los que debe evaluarse la limitación de este derecho y, habiendo definido tal marco de estudio, nos adentraremos en el análisis particular del contenido del citado cuerpo normativo. Sostenemos que, además de ser insuficiente desde la perspectiva internacional, esta ley adolece de problemas técnicos significativos que redundan, en último término, en una serie de problemas asociados a su implementación, según expondremos hacia el final de nuestra investigación.

\section{El derecho frente a la protesta social}

¿Cuál es el sentido de la intervención político-normativa tras los hechos acaecidos con posterioridad al 18 de octubre de 2019? En alguna medida, la respuesta es obvia para todos: la confirmación de una tendencia legislativa impulsada por el Estado de Chile, cuyo objetivo ha sido el fortalecimiento en el resguardo del orden público, por medio de la configuración de nuevos tipos penales, el aumento de las penas ya existentes y la flexibilización en los procedimientos que compete realizar a las policías (Rojas y Valdés, 2013: 33).

En un sentido más profundo, sin embargo, las modificaciones sustantivas introducidas por el legislador dan cuenta de un proceso de transformación que el derecho penal ha experimentado a lo largo de las últimas décadas. Siguiendo a Winfried Hassemer, quien fuera integrante del Tribunal Constitucional alemán, el «nuevo derecho penal» presenta los siguientes rasgos: i) la protección de bienes jurídicos, ii) la exacerbación de la idea de prevención y iii) la reorientación de la praxis jurídico-penal según criterios consecuencialistas (Hassemer, 1999: 47-50).

Aun cuando no es nuestro objetivo ahondar en estas transformaciones, es importante aludir al tercer rasgo que Hassemer identifica. En lo concerniente al sentido de la praxis jurídico-penal, en la actualidad es posible identificar, entre los diversos discursos que convergen en la configuración de la política criminal, la exigencia «por hacer del remedio penal un instrumento de pedagogía social con el fin de "sensibilizar" a la gente». Ello, por cierto, supone conferir a las herramientas del derecho penal un estatus privilegiado entre las opciones político-normativas del Estado ante la conflictividad social. La opción legislativa favorable a la criminalización es entendida como un «instrumento de solución de conflictos sociales que no se diferencia ni en su idoneidad ni en su peligrosidad de otros instrumentos de solución social» (Hassemer, 1999: 51).

Tomando en consideración lo anterior, ¿cómo podríamos caracterizar las inno- 
vaciones legislativas en relación con las protestas sociales? Para hacer frente a ello, es necesaria otra prevención. Los criterios sustantivos que sirven de base a la política criminal no son triviales; por el contrario, la pregunta por la intervención del derecho penal y sus instrumentos es una pregunta - cabe recordarlo- política. Como bien lo ha señalado Juan Pablo Mañalich (2018), las decisiones concernientes a la definición, el control y la represión de comportamientos socialmente reprochables no son políticamente neutras. Cualquier operación que persiguiere desligarlas de la polemicidad que les es esencial solo podría descansar en la cándida idea conforme a la que existirían premisas político-criminales «universales».

Volvamos a la pregunta inicial: ¿cuál es el sentido de la intervención políticonormativa tras los hechos acaecidos durante el «estallido social»? Convergen en esta definición discursos que favorecen la opción criminalizadora frente al aumento de la conflictividad social. ¿Qué relación particular puede existir entre esta opción política concreta y la protesta social, entendiéndola como una forma de ejercicio de la autodeterminación política? No olvidemos, el derecho de ciudadanos y ciudadanas de participar activamente en el proceso de formación de la opinión y la voluntad política es uno de los elementos indispensables de una comunidad democrática. Dada la importancia de la que está revestido, las limitaciones legales que pudiere imponer el Estado deberán estar supeditadas a las exigencias sustantivas que se desprendan del programa democrático. ${ }^{1}$ El derecho a manifestarse - uno de los cauces a través de los que se canaliza la participación política ciudadana- no puede verse vulnerado, entonces, por la entidad estatal, a pretexto de resguardar la seguridad ciudadana y la estabilidad del orden público.

El conflicto político y su expresión a través de la protesta social ilustra con especial nitidez la tensión que, de forma más menos indefectible, todo orden constitucional reproduce: la aspiración, por una parte, de resguardar el programa democrático y, por otra, de resguardar los derechos de ciudadanos y ciudadanas (Gargarella, 2015: 2). ¿Qué explica esta tensión? Cuando los operadores jurídicos se encuentran frente a un conflicto que involucra la protesta social, deben expresarse sobre el modo en que ellos mismos piensan la democracia. La participación política excede al cauce institucional del sufragio. Ello es especialmente relevante si se considera cómo el Estado atiende a las manifestaciones de la ciudadanía y cómo apuesta por resolver las even-

1. El empleo de esta expresión se asocia a los problemas múltiples de significación que admite el término democracia. Al respecto, cabe tener presente - como bien lo indicara Alf Ross- que la democracia no constituye una forma institucional rígida. Por el contrario, puede entenderse como un horizonte en relación con el que las formas institucionales se evalúan — lo que Ross denomina «ideal carente de realidad»-. Por consiguiente, más allá de implicar un diseño institucional concreto, esta supone un principio organizacional respecto de la titularidad y el ejercicio del poder político. La implementación técnica y la consecución institucional del referido horizonte no es, en ningún caso, invariable. Al respecto, véase Ross (1989). 
tuales colisiones entre derechos de la ciudadanía. ${ }^{2}$ La acción estatal y el consiguiente desarrollo de la legislación no puede afectar el derecho a la manifestación pública, sobre todo cuando dicha intervención adquiere el grado de intensidad característico del derecho penal.

\section{Marco normativo internacional y nacional sobre el derecho a la protesta}

Es necesario señalar que, desde una perspectiva normativa, el «derecho a la protesta social $»^{3}$ no se encuentra reconocido expresamente en los tratados internacionales de derechos humanos. Tampoco en el catálogo de garantías fundamentales de nuestro texto constitucional vigente. No obstante, se ha entendido que es un derecho que se desprende de otros derechos que están consagrados, tanto en el ordenamiento internacional como nacional: el derecho de reunión y la libertad de expresión. ${ }^{4}$

\section{Instrumentos normativos}

Ambos derechos se reconocen ampliamente en el contexto internacional. El derecho a reunión se encuentra reconocido en el artículo 20 de la Declaración Universal de Derechos Humanos (DUDH), el artículo 21 del Pacto Internacional de Derechos Civiles y Políticos (PIDCP), el artículo 5 de la Convención Internacional sobre la eliminación de todas las formas de discriminación racial, el artículo 15 de la Convención sobre los Derechos del Niño, el artículo 21 de la Declaración Americana de los Derechos y Deberes del Hombre (DADDH), el artículo 15 de la Convención Americana sobre Derechos Humanos (CADH) y en los artículos 9 y 22 de la Carta Africana de Derechos Humanos y de los Pueblos.

La presencia de este derecho en tan diversos tratados se explica por su importancia: además de servir de cauce para el ejercicio de otros derechos civiles, culturales,

2. Sobre este punto, es interesante notar el alcance de las discusiones que precedieron a la consagración del derecho a reunión en la actual Constitución. En efecto, aun cuando los comisionados reconocen su importancia en lo que concierne a la vitalidad democrática, no existe una acabada comprensión del sentido de este derecho. Particularmente ilustrativa resultan las palabras del comisionado Guzmán: «Si el día de mañana se dijera que, en los radios urbanos, no se admitirán concentraciones o reuniones masivas en las plazas y calles, piensa que realmente no se estaría vulnerando ningún derecho fundamental, ya que existen otros lugares más alejados de las ciudades en los cuales estas reuniones se pueden verificar». Véase Cox (2010).

3. El empleo del término derecho implica la existencia de un deber correlativo. Cuando se sostiene que la ciudadanía tiene «derecho» a protestar, lo que se pretende señalar es que existe la obligación política por parte del Estado de respetar formas de participación políticas diversas al ejercicio del sufragio.

4. «Las manifestaciones públicas y la protesta social: Consideraciones desde una perspectiva de derechos humanos», Instituto Nacional De Derechos Humanos, 27 de agosto de 2012, p. 2, Disponible en https://bit.ly/3dfvL4I. 
económicos, políticos y sociales, constituye un elemento para la democracia, y su resguardo es «un valioso indicador para determinar en qué medida los Estados respetan el disfrute de muchos otros derechos humanos» (Kiai, 2012: 34-50). En estrecha relación con ello, las restricciones que establezcan los Estados han de ser excepcionales y deben representar un punto de equilibrio entre los diversos valores en colisión. ${ }^{5}$

Por su parte, el derecho a la libertad de opinión y de expresión también ha sido reconocido en diversos instrumentos. Este se consagra en el artículo 19 DUDH, el artículo 19 PICDCP y el artículo $13 \mathrm{CADH}$. Su propósito es «ser un instrumento mediante el cual las personas colectivamente pueden expresar y manifestar su conformidad o disconformidad a un tema que generalmente es de interés público». ${ }^{6} \mathrm{El}$ debido resguardo a la libertad de expresión constituye un mandato ineludible al que debe responder todo Estado democrático, dada la importancia social de la que está revestida.

El ligamen anterior deviene especialmente claro al observar el desarrollo jurisprudencial que el derecho a la protesta ha tenido en el ámbito norteamericano. En efecto, es posible advertir cómo las discusiones en torno a su existencia, límites y cauces de ejercicio son reconducidas de forma permanente a libertad de expresión. En palabras de Gargarella (2011: 77-78):

Una historia similar se puede contar, en principio, sobre el caso de los Estados Unidos, donde la actividad de los manifestantes fue rápidamente leída en clave de libertad de expresión, lo que aseguró una fuerte protección a dicha actividad. El proceso comenzó con la opinión del luez Brandeis en el caso Stenn con Tile Layer Protective Union, quien afirmó: «Los miembros de un sindicato pueden, sin una autorización especial del Estado, hacer públicos los hechos de una dispuesta laboral, puesto que la libertad de expresión está garantizada por la Constitución nacional».

Por consiguiente, dada su importancia política, el derecho a la libre expresión merece una protección especial y sus expresiones - en particular aquellas que tengan por objeto criticar a las autoridades- merecen la protección legal más férrea.

En el ordenamiento jurídico nacional, como bien es sabido, tampoco se reconoce de forma expresa un «derecho a la protesta». Más bien, ha sido reconocido sobre la base de la consagración normativa de los derechos recién precitados en el texto constitucional vigente: el numeral 12 del artículo 19, disposición que asegura a todas las personas «la libertad de emitir opinión y la de informar, sin censura previa, en cualquier forma y por cualquier medio» y el numeral 13, que por su parte reconoce «el derecho a reunirse pacíficamente sin permiso previo y sin armas. Las reuniones en las plazas, calles y demás lugares de uso público, se regirán por las disposiciones generales de policía».

5. INDH, «Las manifestaciones...», 5.

6. INDH, «Las manifestaciones...», 3 . 


\section{Limitaciones a la protesta social: Estándares internacionales y nacionales}

Como ya sostuvimos, la relación entre los aludidos derechos y el resguardo del orden público es especialmente tensa. Así, la vinculación entre ambos suele caracterizarse como una hipótesis clásica de colisión de derechos; por una parte, la libertad de circulación y la seguridad del orden público y, por otra, la posibilidad de realizar manifestaciones en lugares públicos. Los esfuerzos de los operadores jurídicos deben apuntar a identificar un «justo punto de equilibrio» que no involucre el sacrificio de uno en beneficio del otro.

Francisco Cox (2010: 76), al referirse a la importancia política de la protesta, señala que quien se manifiesta persigue, a lo menos, dos propósitos:

El primero llamar la atención de las autoridades y también el resto de la ciudadanía para que apoyen o dejen de apoyar determinadas políticas públicas (o incluso privadas como en el caso de una huelga laboral). Y el segundo, comunicar su postura frente a determinada situación que le o les afecta y lograr obtener la notoriedad e influencia que otros mecanismos más institucionales le han vedado.

De ello se desprende que la protesta constituye una forma de participación política, ajena a los cauces institucionalmente establecidos al efecto. Desde una perspectiva democrática, no cabe restringir en exceso esta posibilidad; es más, cualquier eventual limitación debe fundarse necesariamente sobre las exigencias propias de un orden democráticamente organizado. Por ello, no es adecuado conferir un tratamiento normativo a la protesta social que la equipare o reduzca al «desorden público». Por el contrario, un tratamiento adecuado exige ponderar los valores jurídicos en juego de forma tal que no desnaturalicen el contenido del derecho a manifestarse - el que es consubstancial a la ciudadanía y al libre juego democrático, como ya se ha dicho-. Cualquier invocación a conceptos como seguridad ciudadana u orden público y su consiguiente implementación político-normativa deben tener en estricta consideración este punto.

¿Qué estándares se reconocen a nivel internacional? La Corte IDH, en relación con las exigencias de la $\mathrm{CADH}$, ha contribuido enormemente en sentar criterios sobre este punto: i) toda limitación debe estar establecida por ley; ii) la limitación debe tener un fin legítimo; y iii) debe considerarse necesario en una sociedad democrática. ${ }^{7}$

Toda limitación debe estar establecida por ley: Dado que la protesta debe ser tole-

7. Cabe hacer presente, sin embargo, que el examen de estos elementos no se asocia de forma exclusiva a la limitación del derecho de reunión y la libertad de expresión. Por el contrario, como bien señalan Rojas y Valdés (2013), estas consideraciones forman parte de cualquier análisis de proporcionalidad que se efectúe en lo que concierne a la limitación de garantías fundamentales. Por consiguiente, huelga decir -a riesgo de ser reiterativos- que nuestro interés se restringe a delimitar cómo se han ponderado estas en relación con la protesta social. 
rada por regla general, las eventuales limitaciones no pueden sino ser excepcionales. En efecto, deben establecerse de forma taxativa, precisa y clara. Sobre este punto, la CIDH ha sido enfática en cuanto al alcance de la expresión ley: solo la ley en un sentido estrictamente formal tiene la aptitud requerida para restringir el goce o el ejercicio de los derechos reconocidos por la CADH. En consecuencia, las normas que definan las condiciones de ejercicio del presente derecho deben tener un alcance de carácter general, ceñirse al bien común, emanar de los órganos legislativos constitucionalmente previstos y democráticamente elegido y ser elaborada según los procedimientos establecidos por la constitución para la formación de leyes (CIDH, 2019: 5).

$\mathrm{Al}$ evaluar la regulación doméstica a la luz de este estándar, el resultado arrojado es - qué duda cabe - desalentador. Como bien es sabido, las restricciones que establece la Constitución de 1980 respecto al derecho de reunión se encuentran fijados en un decreto administrativo, el que data de la dictadura de Pinochet (Cox, 2010: 81). El referido cuerpo normativo (el Decreto Supremo 1.086, del 16 de septiembre de 1983) se dictó a fin de cumplir con el mandato constitucional consagrado en el inciso segundo del numeral 13 del artículo 19 de la Constitución: «Las reuniones en las plazas, calles y demás lugares de uso público, se regirán por las disposiciones generales de Policía». El artículo 2 del mentado decreto regula la notificación para la celebración de reuniones en lugares de uso público. Según se suele sostener en nuestro medio, el estándar internacional es doblemente incumplido por la normativa interna: tanto desde un punto de vista formal como material, el ya citado decreto establece de una forma manifiestamente clara una restricción al derecho a reunión que carece de toda justificación razonable.

La limitación debe tener un fin legítimo: Las restricciones deben responder a un interés público, de carácter imperativo. Sobre este particular, la CADH establece criterios diferenciados en relación un derecho u otro: en cuanto al derecho de reunión, se estima legítimo condicionar su ejercicio apelando a «la seguridad nacional, la seguridad o el orden público, a protección de la salud o los derechos o libertades de los demás». En lo que respecta a la libertad de expresión, es necesario que la limitación se justifique en función del respeto a los derechos o la reputación de los demás o la protección de la seguridad nacional, el orden público o la salud o la moral públicas.

En relación con ello, cabe preguntarse: ¿bajo qué razones el Estado de Chile ha restringido el ejercicio del mentado derecho? No sorprende constatar la recurrente invocación al «orden público» en los diversos discursos que convergen en la política de criminalización emprendida al respecto. Sobre este particular y cómo se relaciona con la Ley 21.208, volveremos más adelante.

El fin debe considerarse necesario en una sociedad democrática: El carácter necesario de la restricción debe considerar las exigencias sustantivas aparejadas al modelo institucional democrático y su respectiva implementación programática. Ello se explica por la importancia de la protesta social y las formas de participación «no 
institucionales» en lo que concierne al ejercicio del poder en una comunidad democráticamente organizada. En esta línea, en cuanto a los alcances del término necesario, la CIDH ha sido enfática en señalar que debe relacionarse con una exigencia social, cierta e imperiosa, de forma tal que el objetivo socialmente deseable no pueda alcanzarse por una vía menos restrictiva de los derechos humanos (CIDH, 2019: 19). La limitación no debe ir más allá de lo estrictamente indispensable, lo que supone que estas jamás imposibiliten el ejercicio de los derechos que se pretenden restringir.

¿Qué cabe decir al respecto al analizar el ordenamiento nacional? Al tomar en consideración los rasgos sobresalientes de la tendencia legislativa a la que hiciéramos referencia, se evidencia con nitidez que la opción que emprende el Estado de Chile favorece las herramientas del derecho penal, que son las más intensas.

\section{La Ley 21.208}

La Ley 21.208, conocida como «ley antisaqueos» 0 «ley antibarricadas», tuvo por objeto la introducción de modificaciones en el Código Penal chileno respecto a delitos contra el orden público y contra la propiedad. En un principio se buscó modificar el delito de desórdenes públicos, y finalmente se optó por la creación de un nuevo tipo penal denominado «interrupción de la libre circulación», de forma tal que se sanciona de manera más severa conductas que se producen generalmente en contextos de manifestación social. Incluso, en su inciso final se indica que en el caso de que los hechos previstos en este artículo constituyeren un delito más grave, se aplicará la pena señalada sin atención a su grado mínimo o mínimum, lo que evidencia una agravación de la pena en atención al contexto en que ellos se producen.

Cabe mencionar que, sin perjuicio de que el presente trabajo se refiere únicamente a las modificaciones respecto a los delitos conta el orden público y a la introducción del delito de interrupción a la libre circulación, se le denominó «ley antisaqueos» en atención a las reformas que tienen por objeto la modificación de los delitos contra la propiedad, siguiendo con la lógica de reformas anteriores a dicho grupo de delitos: la «agenda corta antidelincuencia». Esto implica, a diferencia de la creación de un tipo penal específico, una agravación de la pena de un delito ya existente, a través de la modificación de normas de determinación de la pena, que agrava la sanción cuando se cometen delitos contra la propiedad con ocasión de calamidad pública o alteración al orden público ${ }^{8}$ y aplican las normas para reincidentes de este tipo de delitos incluso

8. Código Penal, artículo 449 ter: «Cuando los delitos sancionados en los párrafos 3 y 4 de este título se perpetraren con ocasión de calamidad pública o alteración del orden público, sea que se actúe en grupo o individualmente pero amparado en este, se aumentará la pena privativa de libertad respectiva en un grado. Tratándose de la conducta sancionada en el inciso primero del artículo 436, y concurriendo las circunstancias descritas en el inciso anterior, se aplicará la pena privativa de libertad respectiva, con exclusión de su grado mínimo». 
no teniendo esta calidad, cuando se comete en circunstancias tales que contribuyan a la sustracción o destrucción de todo o la mayor parte de lo que había o se guardaba en un establecimiento o el establecimiento en sí, denominándolo saqueo. ${ }^{9}$

Ahora bien, respecto al derecho a la protesta, por la Ley 21.208, y para el objeto del presente análisis, en su denominación de «ley antibarricadas» revela desde su formación un cuestionamiento al tipo penal de desórdenes públicos en el contexto de manifestaciones sociales, específicamente a raíz de lo ocurrido durante el «estallido social chileno». Por esta razón, es necesario un somero análisis de la discusión llevada a cabo en su tramitación legislativa antes de adentrarnos en el estudio de las modificaciones propiamente tales.

En este sentido, lo primero que llama la atención es el uso de una distinción entre aquellas personas que quieren «manifestarse» en contraposición a quienes prefieren «delinquir» en contextos de manifestaciones sociales, cuestión que permea toda la discusión parlamentaria desde el inicio de su tramitación. Así, se evidencian maneras de protestar y de representar intereses desde la ciudadanía que conllevan inevitablemente la comisión de hechos delictuales, ya sea a través de grupos organizados o personas que individualmente sostienen dichas conductas, fenómeno que exige, a juicio de los parlamentarios que presentan el proyecto, la necesidad de fortalecer la paz social y castigar de forma efectiva a quienes prefieren delinquir frente a quienes «desean que su voz se escuche de manera no violenta». ${ }^{10}$

Así, la iniciativa parlamentaria distingue y define la forma legítima de manifestarse, buscando por lo tanto sancionar aquellas formas consideradas ilícitas - agresivas o violentas- a través de normas penales, puesto que no se propone ningún otro tipo de regulación, ya sea preventiva o de orden administrativo. También identifica en el mismo plano la actuación en grupo («grupos organizados que prefieren la violencia y la utilizan») y la actuación individual («personas que sin coordinación alguna sostienen estas conductas»), pues, a juicio de este grupo parlamentario, son conductas que se generarían de forma inevitable en los contextos de protesta y manifestación. Finalmente, da énfasis al objetivo de fortalecimiento de la paz social, lo que será relevante al abordar el bien jurídico protegido respecto al delito de desórdenes públicos.

Tal y como adelantamos, la discusión parlamentaria respecto a los delitos contra

9. Código Penal, artículo 449 quater: «Se aplicará en todo caso la regla segunda del artículo 449, aun cuando el responsable no sea reincidente, si los delitos señalados en dicho artículo se cometen en circunstancias tales que contribuyan a la sustracción o destrucción de todo o la mayor parte de aquello que había o se guardaba en algún establecimiento de comercio o industrial o del propio establecimiento. En estos casos el hecho se denominará saqueo. Si el responsable fuere reincidente en los términos de las circunstancias agravantes de los numerales 15 y 16 del artículo 12, el juez podrá considerar suficiente fundamento esta circunstancia para la imposición del máximo de la pena resultante».

10. Historia de la Ley 21.208, Biblioteca del Congreso Nacional de Chile, p. 3, disponible en https:// bit.ly/3rjHZim. 
el orden público se centra en la insuficiencia y desactualización del tipo penal de desórdenes públicos, contenido en el artículo 269 del Código Penal chileno. Si bien se analizó la posibilidad de su reformulación, esto fue desestimado optándose por la creación de un tipo penal específico a la interrupción de la libre circulación y el lanzamiento de objetos en la vía pública.

Antes de adentrarnos al análisis del nuevo tipo penal, quisiéramos desarrollar algunos argumentos respecto a la supuesta desactualización del delito de desórdenes públicos. La discusión parlamentaria indica que existirían ciertas complejidades en la norma que producen consecuencias prácticas no deseadas: no protege la seguridad pública, dificulta la labor del órgano persecutor penal y promueve el desgaste policial para efectos de la detención de los delincuentes. ${ }^{11}$

Dicha discusión, como señala Libertad y Desarrollo, ${ }^{12}$ se enmarca en el contexto del estallido social, porque evidenció la incapacidad de las Fuerzas de Orden y Seguridad para el control de la ciudadanía, de forma tal que la regulación del delito de desórdenes generaba impunidad al igual que en el caso de cometer saqueos en locales comerciales en los mismos contextos. A juicio de los promotores del proyecto de ley, el delito de desórdenes públicos se identifica como un tipo penal «desactualizado» e «insuficiente» para hacer frente a dichas actuaciones, puesto que requiere que los desmanes «turben gravemente la tranquilidad pública», logren "provocar injuria a una persona particular» o «cualquier otro fin reprobado». Es decir, el delito de desórdenes público exige una conducta grave que no permite el control de la ciudadanía.

Ahora, los requisitos del tipo penal de desórdenes públicos, analizados por van Weezel (2013), no son exigencias problemáticas de la redacción del delito, sino que van ligadas a una interpretación - que en nuestro concepto es correcta- coherente con la idea del derecho penal como ultima ratio, interpretación acorde a los principios de una sociedad democrática y a los estándares internacionales de derechos humanos. También es coherente con una interpretación sistemática de nuestro ordenamiento jurídico, pues existen faltas penales que refieren a desórdenes públicos, por lo que debe existir un análisis sobre la gravedad de los hechos, aplicando la norma que regule el supuesto de hecho de la mejor forma.

Finalmente, respecto a la aplicación de tipos penales que tienen por objeto la protección indirecta de la seguridad o el orden público, estos bienes jurídicos deben considerarse desde una esfera de la protección de la vida e integridad de terceras personas, sobre todo en contextos en que existe una colisión de derechos fundamentales. Esta colisión, tal y como lo hemos descrito anteriormente, hace imperativo el deber de los jueces de exigir actos que expresen un injusto o un reproche superior y realizar

11. Historia de la Ley 21.208, p. 4.

12. «Agenda de orden público: Recuperar el Estado de derecho», Temas Públicos, 29 de noviembre de 2019, p. 5, disponible en https://bit.ly/3yoQEsC. 
una ponderación entre los derechos en colisión, de forma tal que la limitación del derecho a la manifestación sea razonable y proporcional.

Las exigencias que se cuestionan también derivan de la historia del delito de desórdenes públicos, delito que, si bien tiene su origen en el derecho penal español -que en su redacción antigua refería a un delito político - como una forma tenue o leve de insurrección o rebelión (Weezel, 2013: 102), en Chile se desestimó dicha calificación (Cuellar, 2017: 612) incorporándose al título sexto del libro segundo del Código Penal, «De los crímenes y simples delitos contra el orden y la seguridad públicos cometidos por particulares». Respecto a dicho título, se ha identificado por la doctrina y por la jurisprudencia que protege el orden y seguridad pública, en cuanto esta vea afectada la seguridad individual de las personas (Cuellar, 2017: 612; Weezel, 2013: 104).

Es interesante en este sentido que la crítica al delito de desórdenes públicos sea su antigüedad, lo cual, si bien es cierto, no por eso ha dejado de ser aplicado en nuestros tiempos según las variaciones de las necesidades contemporáneas. Incluso en su país de origen, durante 2015 se creó un delito de desórdenes públicos fuera de su carácter político y que también ha sido discutido respecto al derecho a la manifestación, pero incluso ahí se ha reflexionado en torno a su bien jurídico, y se ha entendido que «lo que protegería este tipo delictivo es la vida e integridad física de una pluralidad indefinida de personas» (Colomer, 2017: 13).

De tal forma, dichas exigencias del tipo penal no son meros caprichos del legislador, sino que tienen por fundamento una aplicación racional y coherente con el bien jurídico protegido, que opera como límite al ius puniendi de acuerdo con el ámbito de protección de la norma. Además, y en atención al objeto del presente trabajo, no cualquier hecho en contexto de manifestación va a tener la capacidad de ser sancionado, pues existe una colisión de derechos que, como bien se ha señalado, deben ser ponderados.

Otra de las razones esbozadas para la creación de un delito especial es la insuficiencia de los tipos penales referidos a bienes jurídicos individuales como las lesiones o los daños. A juicio de los parlamentarios, existía una dificultad para sancionar a quienes afecten dichos intereses individuales. Así, se justificaba privilegiar la regulación de un tipo penal de peligro que permitiera la sanción de conductas anteriores a la transgresión de los bienes jurídicos vida, integridad física y propiedad. Consideramos que, más que un problema respecto a la formulación del tipo penal, es un problema asociado a la investigación y la posibilidad de probar que un sujeto particular afecta un bien jurídico individual en contextos en que existe una multitud de personas. Porque ya el delito de desórdenes públicos permite la sanción de una conducta idónea para poner en riesgo la vida o integridad física de las personas, sin necesidad de exigir una lesión efectiva a dichos bienes jurídicos, pues exige una conducta con la capacidad de causar injuria a persona particular u otro fin reprobado.

Desde la imputación individual, el derecho penal en virtud del principio de cul- 
pabilidad, en su aspecto de personalidad de las penas, implica que no pueda aplicarse una sanción a un conjunto de personas, pues debe sancionar una conducta típica, antijurídica y culpable a quien efectivamente - en este caso- despliega dicha conducta.

Así las cosas, una reformulación del tipo penal no soluciona las falencias de investigación o de sustrato material del hecho, y menos aún proponer un tipo de responsabilidad objetiva, pues eso efectivamente es lo que vulneraría en este caso el derecho a la manifestación. Disminuir en este sentido las exigencias del tipo es disminuir las garantías penales de los ciudadanos.

Finalizada su tramitación, se opta por la creación del delito de interrupción a la libre circulación de personas y lanzamiento de objetos potencialmente aptos para causar la muerte o lesiones en el artículo 268 septies en los siguientes términos:

El que, sin estar autorizado, interrumpiere completamente la libre circulación de personas o vehículos en la vía pública, mediante violencia o intimidación en las personas o la instalación de obstáculos levantados en la misma con objetos diversos, será sancionado con la pena de presidio menor en su grado mínimo.

Idéntica pena se impondrá a los que, sin mediar accidente o desperfecto mecánico, interpusieren sus vehículos en la vía, en términos tales de hacer imposible la circulación de otros por esta.

Será castigado con la pena de presidio menor en su grado mínimo a medio el que lanzare a personas o vehículos que se encontraren en la vía pública instrumentos, utensilios u objetos cortantes, punzantes o contundentes potencialmente aptos para causar la muerte o producir lesiones corporales, a menos que el hecho constituya un delito más grave. El tribunal, al momento de determinar la pena, tendrá especialmente en consideración la peligrosidad del instrumento, utensilio u objeto lanzado.

Si alguno de los hechos previstos en este artículo constituyere un delito más grave, se aplicará la pena señalada a este, sin atención a su grado mínimo o mínimum, según los respectivos casos.

\section{Análisis de la modificación introducida en virtud de la Ley 21.208 al Código Penal: El artículo 268 septies}

En primer término, la disposición incorpora la tipificación de la interrupción a la libre circulación, ya sea de personas o de vehículos, a través de violencia o intimidación a las personas, la instalación de obstáculos y la interposición de vehículos. Se decidió introducir el tipo penal dentro del título sexto, al igual que el delito de desórdenes públicos y que, como habíamos expresado antes, «concentra una serie de figuras que tienen como elemento común la afectación de la "seguridad individual" [...] entendida como la ausencia de amenazas relevantes para los bienes o intereses personalísimos, principalmente la vida, integridad corporal, salud, libertad ambulatoria y libertad de determinación» (Cuellar, 2017: 614). 
Desde aquí, parece relevante para la aplicación de la norma determinar qué debemos entender por interrupción del tránsito. Desde una interpretación sistemática, la Ley de Tránsito considera un tipo penal para quien instale señales del tránsito o barreras sin estar facultado para ello $;{ }^{13} \sin$ embargo, dicha normativa sancionaría un supuesto distinto al tipo en comento, pues estaríamos frente a una instalación de objetos específicos (señales o barreras) sin facultad para ello y con un objeto de protección diverso, pues refiere al cumplimiento de las normas referentes al tráfico vial.

En este sentido, la nueva norma busca proteger la libre circulación tanto de las personas como de los vehículos a través de la sanción de la conducta de interrumpir de forma completa. Es decir, exige que no haya otra forma de circulación. Incluso en su discusión legislativa, ${ }^{14}$ relevante desde una interpretación histórica, se plasma la idea de que no basta la mera interrupción, sino que debe ser una interrupción tal que ponga en jaque todo el sistema de transporte, por lo que es necesario analizar el lapso de tiempo respecto a la interrupción y el lugar en donde ocurre, pues es distinta la interrupción en el centro de una ciudad que en la periferia y, además, que la conducta desplegada por el sujeto sea aquella que efectivamente interrumpa de forma seria y grave la circulación. Desde ahí, que la interrupción en este tipo penal debe ser aquella que impide la libre circulación de las personas de forma tal que no exista otra forma razonable de circulación.

También exige medios comisivos específicos, ya que la instalación de obstáculos o la interposición de vehículos debe hacerse a través de violencia o intimidación contra las personas. Respecto a la violencia o intimidación contra las personas, el Código Penal lo define a propósito de los delitos contra la propiedad en su artículo 439. Sin perjuicio de ello, se ha entendido como un elemento de daño o peligro concreto para la seguridad y la integridad de las personas y, para algunos autores, como un elemento de coacción (Matus y Ramírez, 2019: 294). De tal forma, la redacción del tipo penal es ineficiente en el sentido de que, al entender que la seguridad pública debe considerarse respecto a la posibilidad de afectación de la vida o integridad de terceras personas, reitera un elemento que ya debe analizarse a propósito de que la conducta de interrumpir sea idónea para poder afectar dicho bien jurídico. Además, porque la violencia — entendida como una fuerza física usada sobre las personas- o la intimidación —entendida como una amenaza de ocasionar un mal- podrían ser constitutivos de delito por sí mismas, sin necesidad de tener una conexión con la interrupción de la libre circulación, por lo que esta conexión meramente contextual

13. Ley 18.120, Ley del Tránsito, artículo 191: «El que instale señales de tránsito o barreras sin estar facultado para ello, salvo en caso de siniestro o accidente, será penado con multa de ocho a dieciséis unidades tributarias mensuales, además del comiso de las especies. Se presumirá como autor de esta infracción a la persona natural o jurídica beneficiada con la infracción».

14. Historia de la Ley 21.208, p. 25. 
sería una agravación de la pena en el caso de que el delito sea más grave, lo cual desarrollaremos al final del texto.

Por otro lado, no deja de sorprender que se equipare la interrupción a la libre circulación mediante violencia o intimidación con la interrupción a través de objetos materiales como obstáculos o vehículos. Esto no parece a nuestro juicio razonable desde un análisis de proporcionalidad, pues la instalación de objetos no puede configurar en abstracto un delito como sí pudiese configurar la violencia o intimidación contra las personas, salvo que dichos obstáculos hayan sido obtenidos de forma ilícita. Esta idea de la propiedad del objeto usado para la interrupción también es relevante a propósito de los vehículos, ya que en el inciso segundo sanciona con la misma pena a quien sin mediar accidente o desperfecto mecánico interpusiere sus vehículos en la vía en términos tales de hacer imposible la circulación de otros. Esto revela que se asimilan situaciones que no significan un aumento del peligro o del injusto respecto a la seguridad pública, pues para dicho efecto es irrelevante la propiedad del vehículo u objeto.

En atención a esto, cabe preguntar, en un contexto de protesta, ¿podría aplicarse este tipo penal a un grupo de personas con pancartas? ¿Es igualmente reprochable la interrupción a través de una barricada con fuego? Es interesante haberse planteado como objetivo de esta incorporación el aumento de la posibilidad de castigo, ya que, tanto desde la óptica de ponderación de derechos en colisión como el sentido de la redacción de la norma, una barricada — por sí misma - no cumple los requisitos de violencia o intimidación hacia las personas, sin perjuicio de que en un caso concreto podría ser más peligroso, así como una pancarta no podría considerarse como un obstáculo objetivo frente a un vehículo. Por lo mismo, no cualquier interrupción puede ser objeto de una sanción, menos aún en contextos en que chocan diversos derechos.

La interrupción de la libre circulación ya había sido sancionada en Chile a través del delito de desórdenes públicos, el cual ha sido interpretado por la doctrina y la jurisprudencia bajo la exigencia de una conducta que pusiera en peligro la vida o la integridad de las personas, no solo por la acción de interrupción, sino exigiendo una posibilidad concreta de afectación a dichos bienes jurídicos (Weezel, 2013: 104).

Es por ello por lo que en el derecho comparado se cuestiona si la tipificación de la interrupción del tráfico vial, en estos contextos, no es sino una criminalización de un acto de protesta legítima en tanto no afecte la vida y la libertad de las personas. Así, se ha indicado que «la entidad de los intereses que resultan afectados con los bloqueos de vías no resulta suficiente para justificar su penalización, máxime si se tiene en cuenta que el espacio público no solo es un escenario para la circulación, sino para la participación» (Uprimmy y Sánchez, 2010).

Entender el espacio público como un espacio de participación y la exigencia de analizar la idoneidad de la conducta para poner en peligro, potencialmente, la vida 
e integridad de terceros, es el ejercicio efectivo de ponderación de derechos que los operadores jurídicos deben realizar al momento de la aplicación del tipo penal. Más aún en contextos como manifestaciones o protestas sociales, en que confluyen varios derechos, y en que debería primar el derecho a la manifestación de una forma razonable, con dicho ejercicio como la única forma de definir en el caso concreto su limitación bajo el respeto a la vida e integridad de terceros.

En segundo término, la nueva incorporación incluye en su inciso tercero a quien lanzare, a personas o vehículos que se encontraren en la vía pública, instrumentos, utensilios u objetos cortantes, punzantes o contundentes potencialmente aptos para causar la muerte o producir lesiones, indicando además que el juez al momento de determinar la pena tendrá especialmente en consideración la peligrosidad del instrumento.

El Código Penal chileno ya sanciona a título de falta el lanzamiento de piedras u otros objetos arrojadizos en parajes públicos, con riesgo en los transeúntes o a las casas o edificios, en perjuicio de estos o con peligro de las personas en el artículo 496 numeral 6. Respecto al artículo 268 septies, se limita el lanzamiento respecto a su dirección contra personas o vehículos que se encuentren en la vía pública, sin ser en este caso aplicable, en principio, contra establecimientos o domicilios particulares, en donde se aplicaría la falta de lanzamiento de objetos. La pregunta es si el artículo 268 septies se aplica en el caso en que se lancen piedras en contra de un establecimiento, en que es previsible la existencia de personas en su interior. En este caso, creemos que el mero lanzamiento correspondería a una falta, y que corresponde a otro tipo de delitos respecto a los daños y a las lesiones de personas en el interior, ya que el tipo penal exige específicamente el lanzamiento directo contra las personas.

Respecto a las personas y vehículos, es claramente un adelantamiento de la sanción, en el evento de no poder ser sancionados bajo delito de lesiones o de daños como un delito de mayor gravedad. Es el caso de evitar la sanción de lesiones en grados de desarrollo del delito previos a su consumación y que tienen en abstracto una pena menor que el lanzamiento de objetos, como por ejemplo las lesiones leves.

Pese a los esfuerzos en su redacción, en atención a los argumentos esgrimidos a propósito del deber de ponderación de derechos, el delito de lanzamiento de objetos tal y como se redacta hoy exige un análisis respecto a la peligrosidad no solo de la conducta, sino del objeto respecto a su idoneidad para causar la muerte o producir lesiones corporales. El juez deberá analizar si la conducta de lanzar determinado objeto en un contexto especifico tiene la potencialidad para afectar la vida o la integridad de una persona en abstracto, y en caso contrario preferir la aplicación de la falta existente.

Por ello, es un adelantamiento de la barrera punitiva, porque al calificar que se trata de una conducta idónea para causar la muerte o lesiones corporales de una persona en concreto, se trata de una calificación anterior frente al supuesto de un delito 
de homicidio o lesiones frustrado, por lo que la modificación en sí misma referiría a un elemento de contexto - y a los problemas asociados a este- más que a una protección especial del orden o la seguridad pública desde la protección de derechos de terceros.

En tercer término, se agrega en su inciso final una agravante que indica que, si los hechos previstos en el mismo artículo constituyeren un delito más grave, se aplicará la pena señalada a este, sin atención a su grado mínimo o mínimum. En este caso, se trataría a nuestro juicio de una agravante de contexto, pues a propósito de una interrupción de la circulación o del lanzamiento de objeto contra las personas o vehículos se produjese un delito más grave, deberá eliminar el grado mínimo o el mínimum de la pena asignada al delito. En dicho supuesto, podríamos estar frente a un problema de ne bis in idem, ya que la conducta desplegada para cometer el delito más grave será considerada además para agravar la pena. Es cuestionable que no tenga por fundamento una agravación en virtud de un aumento de lesividad en bienes jurídicos.

En este sentido, la creación del tipo penal del artículo 268 septies del Código Penal chileno tiene por objeto sancionar momentos anteriores a la lesión de un bien jurídico de vida o integridad física, pero que debido a las exigencias de gravedad y de potencialidad (idoneidad de la conducta), debe analizarse como peligro concreto. Consideramos que además será un delito de difícil aplicación, tanto por la prueba de dichas exigencias como por su legitimidad de sanción, ya que es fruto de una discusión legislativa que etiqueta a quienes deciden delinquir en contextos de manifestación social. Si bien a la fecha de publicación no existen datos respecto a su aplicación práctica, creemos que el hecho de que las conductas que se tipifican de forma específica ya habían sido sancionadas con anterioridad a través del delito de desórdenes públicos, no existe una necesidad efectiva de crear un delito nuevo, así como tampoco una agravante.

Así, podríamos estar en un supuesto denominado derecho penal simbólico, en el que se tipifican conductas en que no existía una necesidad de reforzar su sanción o delitos que no recibirán aplicación en nuestro sistema. Dicho supuesto pone en evidencia el uso del derecho penal como un instrumento de pedagogía social, y como la primera herramienta de nuestro legislador para hacer frente a conflictos sociales. Esto significa además un riesgo respecto a los derechos de las y los ciudadanos, ya que puede convertirse en el fundamento para la detención y procesamiento de una persona por un hecho que reviste características de delito, junto con la aplicación de medidas restrictivas de libertad, respecto a hechos que solo constituyen una falta o que no ponen en peligro efectivo los derechos de terceras personas.

Por esto, se deben tener en consideración otros tipos penales que pueden entrar en colisión con estos hechos, como las faltas del artículo 494, numerales 1 y 16, el artículo 495, numerales 1 y 2, y el artículo 496, numeral 26, todos del Código Penal, 
así como también la Ley de Seguridad del Estado. De tal forma, que no se evidencia una proporcionalidad en las conductas sancionadas por el tipo penal contenido en el artículo 268 septies del Código Penal chileno, lo que puede significar que la reforma y su creación sancionen un determinado contexto y no una conducta que efectivamente sea peligrosa o ponga en riesgo bienes jurídicos distintos a los que ya contemplaba nuestro ordenamiento jurídico, ya que no se trataba de conductas atípicas momentos antes de la reforma.

Es por ello que no debemos dejar de recordar que la $\mathrm{CIDH}$ ha indicado que la conducta de participar en una manifestación, interrumpir el tránsito o los actos de desorden en general no afectan la vida o la libertad de las personas, criterios que son usados para calificar como "pacífico» o «legítimo» un acto de protesta dentro de un Estado de derecho (Personería de Medellín, 2010: 139). En este sentido, los intereses jurídicamente relevantes establecidos por el legislador como la paz social, la democracia o la seguridad no pueden ser entendidos ni protegidos sin atender a los bienes jurídicos ya referidos (la vida y la libertad de las personas), porque sin ellos son conceptos indeterminados para la aplicación de un tipo penal en concreto.

\section{Conclusiones}

Evaluada a la luz de los estándares internacionales, la implementación de un programa político-normativo de criminalización por parte del Estado chileno para hacer frente al incremento de la conflictividad social no satisface las exigencias sustantivas a las que debe estar afecta la limitación de las garantías fundamentales involucradas. En efecto, la deficiencia se evidencia desde el punto de vista constitucional —en lo que concierne a la limitación del derecho a reunión en virtud de un cuerpo normativo de jerarquía infralegal - y desde un punto de vista legal — sobre todo en la proliferación de iniciativas legales que en los hechos persiguen expandir de forma desproporcionada las herramientas de intervención penal-.

Respecto a la Ley 21.208 se evidencia que, atendida su tramitación, se dio énfasis a una distinción sin fundamentos respecto a qué debe entenderse como expresión de manifestación legítima, ajena a los estándares e instrumentos internacionales en materia de derechos humanos respecto al derecho a la manifestación social.

Una de las razones que dio origen a la ley antisaqueos fue la desactualización del delito de desórdenes públicos. Sin embargo, las conductas que son tipificadas en el delito contenido en el artículo 268 septies ya eran sancionadas por nuestro ordenamiento jurídico, ya sea a través de faltas o bajo la calificación de desórdenes.

La decisión legislativa de incorporar un nuevo tipo penal en el título sexto del libro segundo del Código Penal chileno, «De los crímenes y simples delitos contra el orden y la seguridad públicos cometidos por particulares», tendría por objeto la protección indirecta del mismo bien jurídico protegido por el delito de desórdenes 
públicos, esto es el orden o la seguridad pública. Dicha protección debe considerar la posibilidad de afectación a los derechos de terceros, en especial a la vida y la integridad física de las personas, pues este es el criterio razonable para limitar el derecho a la manifestación, en contextos de colisión de derechos.

En escenarios de protesta social, es deber de los operadores jurídicos - y en especial de los jueces- interpretar conforme a los estándares internacionales expuestos sobre el derecho a la manifestación, que debe preponderar de forma razonable, con el límite en la posibilidad de daño a la vida e integridad física.

Es cuestionable la utilización del derecho penal para la limitación del derecho a manifestarse. Si bien puede ser limitado a través de la ley, esta no debería tener por objeto únicamente la tipificación de conductas; más aún cuando dentro del mismo tipo penal existe una desproporción entre las conductas, ya que sancionan de la misma forma acciones que no cuentan con la misma peligrosidad respecto a los bienes jurídicos protegidos. A dicha desproporción, se suma la idea de que se sancionan conductas que ya se encontraban tipificadas en el ordenamiento jurídico chileno, por lo que la reforma solo tendría por objeto la agravación de la sanción en abstracto en virtud de un contexto más que de un reproche de la conducta.

\section{Referencias}

Colomer, David (2017). «Reflexiones en torno al bien jurídico protegido en los delitos de desórdenes públicos». Revista Electrónica de Ciencia Penal y Criminología, 19: 1-28. Disponible en https://bit.ly/2ULGD4d.

CIDH, Comisión Interamericana De Derechos Humanos (2019). «Protesta y derechos humanos: Estándares sobre los derechos involucrados en la protesta social y las obligaciones que deben guiar la respuesta estatal». OEA/Ser.L/V/II, CIDH/ RELE/INF.22/19. Disponible en https://bit.ly/3wvvoLs.

Cox, Francisco (2010). «Criminalización de la protesta social: "No tiene derecho a reunirse donde le plazca"». En Eduardo Bertoni (compilador), ¿Es legítima la criminalización de la protesta social? Derecho penal y libertad de expresión en América Latina (pp. 75-99). Buenos Aires: Universidad de Palermo.

Cuellar, Alberto (2017). «El tipo penal de desórdenes públicos en Chile frente al derecho de reunión y a la libertad de expresión en el marco del derecho de manifestación». Justiça do Direito, 31 (3): 603-620. DOI: 10.5335/rjd.v31i3.7838.

HASSEMER, Winfried (1999). Persona, mundo y responsabilidad: Bases para una teoría de la imputación en derecho penal. Valencia: Tirant lo Blanch.

Gargarella, Roberto (2011). «Entre el derecho y la protesta social». Ecuador Debate, 83: 75-94. Disponible en https://bit.ly/2WeLGud.

-. (2015) «El derecho frente a la protesta social». Disponible https://bit.ly/3dgaCqO. 
KIAI, Maina (2012). «Informe del relator especial sobre los derechos a la libertad de reunión pacífica y de asociación» En Protesta social y derechos humanos (pp. 3450). Santiago: Instituto Nacional de Derechos Humanos.

MaÑAlich, Juan Pablo (2018). «El principialismo político-criminal como fetiche». Revista de Estudios de la Justicia, 29: 59-71. Disponible en https://bit.ly/3eUzIN2.

Matus, Jean-Pierre y Cecilia Ramírez (2019). Manual de derecho penal chileno: Parte especial. 3. ${ }^{\text {a }}$ edición actualizada. Valencia: Tirant lo Blanch.

Navarro, Federico y Carlos Tromben (2019). «Estamos en guerra contra un enemigo poderoso, implacable: Los discursos de Sebastián Piñera y la revuelta popular en Chile». Literatura y Lingüística, 40: 295-324. DOI: 10.29344/0717621X.40.2083.

Personería de Medellín (2010). «Protesta social: Entre derecho y delito». Kavilando, 2 (2): 113-212. Disponible en https://bit.ly/3kZkcTN.

Rojas, Nicoll y Diana Valdés (2013). «Constitucionalidad de la tendencia legislativa penal en materia de orden público: Análisis de proyectos de ley años 20102012». Revista de Filosofía y Ciencias Jurídicas, 2: 33-54. Disponible en https://bit. ly/2VepCiP.

Ross, Alf (1989). ¿Por qué democracia? Madrid: Centro de Estudios Constitucionales. Uprimmy, Rodrigo y Luz María Sánchez (2010). «Derecho penal y protesta social». En Eduardo Bertoni (compilador), ¿Es legítima la criminalización de la protesta social? Derecho penal y libertad de expresión en América Latina (pp. 47-74). Buenos Aires: Universidad de Palermo.

WeEZel, Alex van (2013). «Estructura y alcances del injusto típico del delito de desórdenes públicos». En Informes en derecho: Doctrina procesal penal 2012 (pp. 99-138). Volumen 13. Santiago: Centro de Documentación Defensoría Penal Pública.

\section{Sobre los autores}

Mariana Bell Santos es abogada y licenciada en Ciencias Jurídicas y Sociales por la Universidad de Chile. Ayudante de los departamentos de Derecho Público y Ciencias Penales de la Facultad de Derecho de la Universidad de Chile. Su correo es mariana.bell@derecho.uchile.cl. (D) https://orcid.org/oooo-0003-2556-9714.

Martín Fuentes Fernández es abogado y licenciado en Ciencias Jurídicas y Sociales por la Universidad de Chile. Ayudante del Departamento de Ciencias del Derecho de la Facultad de Derecho de la Universidad de Chile. Su correo electrónico es martin.fuentes@derecho.uchile.cl. (D) https://orcid.org/0000-0002-1583-5874. 
El Anuario de Derechos Humanos es una publicación semestral de referencia y consulta en materia de derechos humanos y campos afines. Busca ser un espacio de discusión de los temas centrales en el ámbito nacional e internacional sobre derechos humanos. Es publicado desde 2005 por el Centro de Derechos Humanos de la Facultad de Derecho de la Universidad de Chile.

\author{
EDITORA \\ Claudia Iriarte Rivas \\ ciriarter@derecho.uchile.cl \\ SITIO WEB \\ anuariocdh.uchile.cl \\ CORREO ELECTRÓNICO \\ anuario-cdh@derecho.uchile.cl \\ LICENCIA DE ESTE ARTÍCULO \\ Creative Commons Atribución Compartir Igual 4.o Internacional
}

\author{
\% \\ La edición de textos, el diseño editorial \\ y la conversión a formatos electrónicos de este artículo \\ estuvieron a cargo de Tipográfica \\ (www.tipografica.io)
}

